\title{
Contribuição à taxonomia de Axonopus P. Beauv. (Poaceae) no Estado do Pará, Brasil
}

\author{
Antônio Elielson Sousa da Rocha ${ }^{1,2}$ e Ricardo de S. Secco ${ }^{1}$
}

Recebido em 20/06/2002. Aceito em 11/09/2003

\begin{abstract}
RESUMO - (Contribuição à taxonomia de Axonopus P. Beauv. (Poaceae) no Estado do Pará, Brasil). São apresentadas 22 espécies do gênero Axonopus P. Beauv. para o Estado do Pará. São apresentadas chave de identificação para os táxons, descrições sucintas, distribuição geográfica e ilustrações. Quatro outras espécies previamente citadas para o Estado do Pará são deixadas à parte, aguardando estudos complementares.
\end{abstract}

Palavras-chave: Axonopus, Poaceae, Estado do Pará

ABSTRACT - (Taxonomic contribution to Axonopus P. Beauv. (Poaceae) in Pará State, Brazil). Twenty two species of the genus Axonopus P. Beauv. are cited to Pará State. An identifiaction key is provided, as well as a brief description, geographical distribution and illustration for each species. Four additional species previously mentioned to Pará State are left aside, waiting for further studies.

Key words: Axonopus, Poaceae, Pará State

\section{Introdução}

O gênero Axonopus inclui três seções e cerca de 110 espécies, distribuídas nas regiões tropicais e subtropicais (Clayton \& Renvoize 1986). No Brasil, o gênero está representado por cerca de 75 espécies, sendo que a maioria pertence à seção Axonopus, na qual as espécies apresentam a raque glabra ou pubescente.

No Estado do Pará os indivíduos de Axonopus ocorrem, preferencialmente, em campos de solo seco e impermeável. O material botânico coletado no Estado é procedente de pontos isolados, geralmente dos campos de Marajó, Santarém, Oriximiná, Monte Alegre, Serra dos Carajás, Campos do Ariramba no alto Trombetas e de coletas realizadas no nordeste paraense, basicamente em campinas (Município de Vigia) ou litoral (Municípios de Maracanã e Marapanim).

Os estudos mais amplos tratando as espécies brasileiras foram realizados por Dedecca (1956) e Black (1963). No Estado do Pará, o gênero foi tratado por Bastos (1991), que assinalou cinco espécies para a Serra dos Carajás, no município de Parauapebas, sendo uma nova (Axonopus carajasensis Bastos). As demais publicações resumem-se a listagens de espécies.
Diante da carência de estudos atuais sobre este gênero no Estado, apresenta-se neste trabalho um levantamento atualizado, embora ainda incompleto, das espécies paraenses, fornecendo chave de identificação, descrições sucintas e ilustrações, distribuição geográfica e material examinado, como uma contribuição para futura revisão do táxon.

\section{Material e métodos}

Foi examinado material botânico referente ao gênero Axonopus, coletado no Estado do Pará, depositado nos herbários do Museu Paraense Emílio Goeldi (MG) e Embrapa Amazônia Oriental (IAN). Foi feito levantamento bibliográfico sobre o gênero e analisados 14 exemplares-tipo, incluindo variedades e sinônimos.

De cada espécie foi escolhida uma amostra, na qual foi realizada dissecação com o objetivo de descrevê-la e ilustrá-la. Em seguida foram utilizadas referências específicas para reforçar as identificações e confeccionadas ilustrações de suas espiguetas, sendo mostrada a face dorsal da gluma superior e do lema fértil (Fig. 1 a-z).

1 Museu Paraense Emílio Goeldi, CBO. C. Postal 399, CEP 66040-170, Belém, PA, Brasil

2 Autor para correspondência: aelielson@bol.com.br 


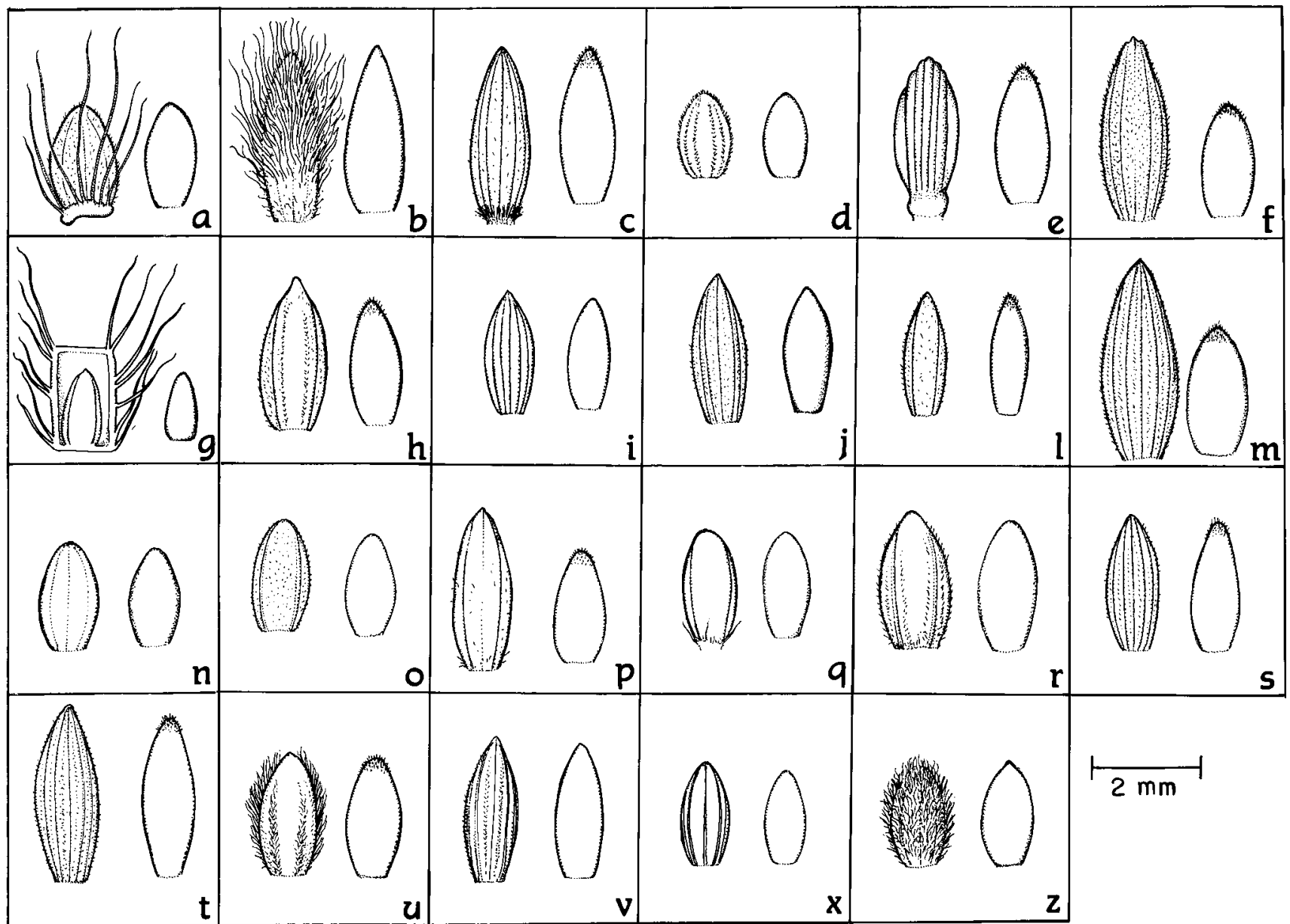

Figura 1. Axonopus P. Beauv. Espigueta - face dorsal da gluma superior e do lema fértil: a. A. aureus. b. A. brasiliensis. c. A. camargoanus. d. A. capillaris. e. A. carajasensis. f. A. centralis. g. A. chrysoblepharis. h. A. compressus. i. A. eminens. j. A. equitans. 1. A. fissifolius. m. A. hitchcockii. n. A. hoehnei. o. A. kaietukensis. p. leptostachyus. q. A. polydactylus. r. A. pressus. s. A. pruinosus. t. A. pubivaginatus. u. A. purpusii. v. A. scoparius. x. A. siccus. z. Axonopus sp.

\section{Resultados e discussão}

Axonopus P. Beauv., Ess. Agrostogr. 12, 154. 1912.

Plantas geralmente perenes, raramente anuais, cespitosas ou estoloníferas, bainhas comprimidas, lígulas ciliadas, lâminas planas ou revolutas. Inflorescência terminal, subterminal ou axilar, racemos espiciformes conjugados, digitados ou subdigitados. Espiguetas oblongas ou ovais, solitárias, sésseis ou curto-pediceladas, alternadas, formando duas fileiras no mesmo lado da raque, o dorso do lema fértil voltado para fora da raque. Gluma inferior ausente, lema estéril membranáceo, geralmente igual em tamanho e textura à gluma superior; lema e pálea férteis cartáceos, lema fértil obtuso com margem abraçando a pálea fértil. Cariópse elíptica.

Axonopus é muito próximo de Paspalum e Digitaria, diferenciando-se destes basicamente por apresentar gluma superior posicionada de maneira inversa, com o dorso do lema fértil voltado para fora da raque. Além da afinidade com os citados gêneros, nota-se também grande afinidade entre suas espécies, algumas com variações morfológicas consideráveis, o que resultou vasta sinonímia.

Chave de identificação para as espécies de Axonopus verificadas no Estado do Pará

1. Planta anual

2. Espigueta 2,2-2,8mm compr., profundamente sulcada entre as nervuras, inflorescência solitária de $2-6$ racemos 
2. Espigueta 0,9-1,3mm compr., não sulcada entre as nervuras, 1-3 inflorescências de 2-3

racemos

4. A. capillaris

1. Planta perene ou de duração indefinida

3. Erva menor que $1 \mathrm{~m}$ alt.

4. Raque ou espiguetas com tricomas longos até $4 \mathrm{~mm}$ compr.

5. Raque e espigueta com tricomas pálidos

2. A. brasiliensis

5. Raque e/ou espiguetas com tricomas dourados

6. Raque com cavidades onde se inserem as espiguetas

7. A. chrysoblepharis

6. Raque sem cavidades 1. A. aureus

4. Raque ou espiguetas glabras, com tricomas curtos ou inconspícuos

7. Espigueta maior que $2 \mathrm{~mm}$ compr.

8. Espigueta 4-nervadas

8. Espigueta 5-nervadas

9. Espigueta 2,9-3,5mm compr., racemos $8-20 \mathrm{~cm}$ compr., lema e pálea férteis menores que a espigueta

6. A. centralis

9. Espigueta 3,1-3,2mm compr., racemos 4-6cm compr., lema e pálea férteis do comprimento da espigueta 3. A. camargoanus

7. Espigueta menor ou igual a $2 \mathrm{~mm}$ compr.

10. Plantas tipicamente cespitosas, raro estolhos, espiguetas pubescentes 20. A. purpusii

10. Plantas estoloníferas, espiguetas quase glabras 11. A. fissifolius

3. Erva de $1-2 \mathrm{~m}$ alt.

11. Lema e pálea férteis menor que a espigueta

12. Espigueta 2,3-2,4mm compr., lema e pálea férteis cerca de $0,2 \mathrm{~mm}$ mais curtos que a espigueta

10. A. equitans

12. Espigueta maior que $2,5 \mathrm{~mm}$ de compr., lema e pálea férteis $2 / 3$ do comprimento da espigueta

13. Espigueta 2,8-3,0mm compr., 2-nervadas

15. A. leptostachyus

13. Espigueta 3,0-3,8mm compr., 5-nervadas 12. A. hitchcockii

11. Lema e pálea férteis do comprimento da espigueta

14. Espigueta maior que $2,2 \mathrm{~mm}$ compr.

15. Espigueta 2-4-nervadas

17. A. pressus

15. Espigueta 5-nervadas

16. Eixo da inflorescência $15-25 \mathrm{~cm}$ compr., com os racemos agregados na extremidade, nós glabros

21. A. scoparius

16. Eixo da inflorescência $2-10 \mathrm{~cm}$ compr., com os racemos não agregados na extremidade, nós pilosos

19. A. pubivaginatus

14. Espigueta menor ou igual a $2 \mathrm{~mm}$ compr.

17. Espigueta 5-nervadas, lema e pálea férteis branco ou amarelados

18. Inflorescência com cerca de 100 racemos, ápice do lema e pálea férteis pubescentes 18. A. pruinosus

18. Inflorescência com até 30 racemos, ápice do lema e pálea férteis glabros

19. Inflorescência sempre solitária, lâmina foliar $10-100 \mathrm{~cm}$ compr., com base semelhante a um pecíolo

9. A. eminens

19. Inflorescência 1-2 por colmo, lâmina foliar $5-40 \mathrm{~cm}$ compr., com base não semelhante a um pecíolo 22. A. siccus

17. Espigueta 2 ou 3-nervadas, lema e pálea férteis castanho escuros

20. Espigueta com tricomas junto ao ápice do pedicelo

16. A. polydactylus

20. Espigueta sem tricomas junto ao ápice do pedicelo

21. Racemos de 15-30, espigueta 2-nervada, lema e pálea férteis com ápices glabros

14. A. kaietukensis

21. Racemos 13, espigueta 2-3-nervada, lema e pálea férteis com ápices pubescentes 
1. Axonopus aureus P. Beauv., Ess. Agrostogr. 12. 1812.

Fig. 1 a.

Perene, cespitosa, levemente pilosa, $40-90 \mathrm{~cm}$ alt.; inflorescência solitária, pedúnculo 10-4,5 cm compr., eixo $0-3 \mathrm{~cm}$ compr., até 12 racemos próximos entre si, 4-12cm compr., tricomas amarelos dourados até $3 \mathrm{~mm}$ compr., saindo de uma região calosa na base da espigueta e da raque; espigueta $1,1-1,7 \mathrm{~mm}$ compr., $0,5-0,7 \mathrm{~mm}$ larg., 2-3 nervadas, glabra ou sedosa, pubescente com tricomas curtos; lema e pálea férteis pardacentos, do comprimento da espigueta, com ápices glabros.

Distribuição geográfica: do Brasil ao México.

Material examinado: BRASIL. Pará: Óbidos, 26/VI/1960, P. Cavalcante 830 (MG). Paru, 19/II/1970, P. Cavalcante 2412 (MG). Santarém, 23/IV/1981, B. Nelson 1132 (MG). Santarém, 25/I/1934, Swallen 3262 (IAN). Tapajós, Rio Cururu, 8/II/1960, Egler 1260 (MG). Vigia, 30/III/1980, Davidse et al. 17605 (MG). Vigia, 22/I/1958, G.A. Black 50-8744 (IAN) Conceição do Araguaia, 20/II/1980, T. Plowman et al. 8951 (MG). Belém, 29/XI/1956, G.A. Black 56-18927 (IAN). Muaná, 25/IV/1982, M. Dantas \& S. Nivaldo 1196 (IAN). Ariramba, 26/V/1957, G.A. Black et al. 57-19.658 (IAN).

Axonopus pulcher (Nees) Kuhlm, A. sprucei Black, A. canescens (Nees) Pilg., A. chrysites (Steud.) Kuhlm e A. exasperatus (Nees) G.A. Black são aqui aceitos na sinonímia de $A$. aureus, concordando com Renvoize (1984), Judziewicz (1990), Cremers \& Hoff (1993) e Filgueiras (1995).

2. Axonopus brasiliensis (Sprengel) Kuhlm., Comm. Lin. Telegr., Bot. 67(Bot. 11):47. 1922.

Eriochloa brasiliensis Spreng., Syst. Veg. 1:249. 1825.

Fig. 1 b.

Perene, cespitosa, glabra ou levemente pilosa, até $80 \mathrm{~cm}$ alt.; inflorescência solitária, pedúnculo $15-50 \mathrm{~cm}$ compr., eixo 0-2cm compr., 2-6 racemos conjugados ou sub-digitados, até $20 \mathrm{~cm}$ compr., raque flexuosa, cerca de $0,5 \mathrm{~mm}$ larg., triquetra com tricomas ao longo das margens; espigueta 2,2-4,5mm compr., 0,7-1,2mm larg., 3-5-nervadas com tricomas longos, pálidos, sedosos revestindo a gluma superior e lema estéril; lema e pálea férteis pardo-escuros, do comprimento da espigueta, com ápices glabros.

Distribuição geográfica: Paraguai e Brasil (GO, MA, MG, MT, PA, PR, SP e SC).
Material examinado: BRASIL. Pará: Alto Tapajós, 3/II/1960, Egler 1251 (MG).

3. Axonopus camargoanus G.A. Black, Advancing Frontiers Pl. Sci. 5: 102. 1963

Fig. $1 \mathrm{c}$.

Perene, cespitosa até $50 \mathrm{~cm}$ compr., glabra; lâminas estreitas. Inflorescência solitária, pedúnculo 20-25cm compr., eixo até $5 \mathrm{~cm}$ compr., 2-4 racemos, 4-6cm compr.; raque triquetra escabrosa, glabra ou glabriúscula, com axila pilosa; espigueta 3,1-3,2mm compr., $1 \mathrm{~mm}$ larg., geralmente 5-nervadas; gluma superior e lema estéril pubescentes, lema e pálea férteis do comprimento da espigueta, amarelos, com ápices pubescentes.

Distribuição geográfica: Brasil (PA).

Material examinado: BRASIL. Pará: Maicuru, Passagem Nova, 16/VIII/1955, G. A. Black 55-18676 (Isótipo IAN).

Axonopus camargoanus é próxima de A. pubivaginatus, mas separa-se desta basicamente pelo menor número de racemos (2-4) e o maior tamanho da espigueta, que mede cerca de $3 \mathrm{~mm}$ compr.

4. Axonopus capillaris (Lam.) Chase, Proc. Biol. Soc. Wash. 24: 133. 1911.

Paspalum capillare Lam., Tabl. Encycl. 1:176. 1791.

Fig. 1 d.

Anual, decumbente, $30-80 \mathrm{~cm}$ compr., glabra ou mais ou menos pilosa; inflorescência $1-2$, pedúnculo 8-16 cm compr., eixo 2,5-4cm compr., 2-3 racemos conjugados ou subdigitados, $2-6 \mathrm{~cm}$ compr.; raque compressa, da mesma largura da raque, subflexuosa, glabra, com margem inconspicuamente escabrosa; espigueta 0,9-1,3mm compr., 4-nervadas, pubescente sobre as nervuras, lema e pálea férteis do comprimento da espigueta, esbranquiçadas, ápices glabros.

Distribuição geográfica: América Central, Paraguai e Brasil (AM, AC, PA, CE, PI, RN, PE, AL, BA, MG e MT).

Material examinado: BRASIL. Pará: Santarém, 4/1950, Spruce 2669 (MG). Campo do Ariramba, localidade Poções, 12/VI/1957, W.A. Egler 586 (MG). Aramanahy, Rio Tapajós, 14-17/I/1934, J.R. Swallen 03217 (MG). Belém, 14/V/1954, G.A. Black 54-16171 (IAN). Marabá, Serra dos Carajás, 20/III/1984, A.S.L. da Silva et al. 1923 (MG). Belém, 11/1913, A. Goeldi s.n. (in MG 14817). Oriximiná, 11/VI/1957, G.A. Black et al. 57-19984 (IAN). 
Dentre as espécies levantadas, A. capillaris e A. chrysoblepharis apresentam as menores espiguetas, entre $0,9-1,3 \mathrm{~mm}$ compr., sendo que na primeira a raque é glabra e na segunda apresenta tricomas longos e cavidades onde se inserem as espiguetas.

5. Axonopus carajasensis M.N. Bastos, Bol. Mus. Para. Emílio Goeldi Ser. Bot., 7(2): 473-483. 1991.

Fig. $1 \mathrm{e}$.

Anual, glabra a pilosa, $60-80 \mathrm{~cm}$ alt.; inflorescência solitária, pedúnculo 40-50cm compr., 2-6 racemos de $7-13 \mathrm{~cm}$ compr.; raque flexuosa; espigueta $2,2-2,8 \mathrm{~mm}$ compr., 5-7-nervadas, profundamente sulcada entre as nervuras, glabra, lema e pálea férteis, $0,2-0,3 \mathrm{~mm}$ mais curto que a espigueta, com ápices pubescentes.

Distribuição geográfica: Brasil (PA).

Material examinado: BRASIL. Pará: Marabá, Serra dos Carajás, 13/XII/1981, D.C. Daly, R. Callejas et al. 1990 (Holótipo MG).

6. Axonopus centralis Chase, J. Wash. Acad. Sci. 17: 143.1927.

Fig. 1 f.

Perene, cespitosa, glabra ou ciliada na base da lâmina, 35-90cm alt.; inflorescência 2-3, pedúnculo até $40 \mathrm{~cm}$ compr., eixo 0-4cm compr., 2-10 racemos, geralmente 2-3, 8-20cm compr.; raque triquetra, cerca de $1 \mathrm{~mm}$ larg., glabra ou glabriúscula, base pilosa, margem escabrosa; espigueta 2,9-3,5mm compr., 0,8-1 mm larg., pubescente, 3-5-nervadas, com a nervura central parcialmente suprimida ou inconspícua; gluma superior e lema estéril diminutamente 3-dentados no ápice, glabros; lema e pálea férteis 1,6-2mm compr., amarela, com ápices pubescentes.

Distribuição geográfica: do Brasil ao México, Panamá, Equador e Venezuela.

Material examinado: BRASIL. Pará: Cachoeira do Arari, 23/X/1982, M.P. Neves et al. 288 (IAN). Ariramba, 2/VI/1957, G.A. Black et al. 57-19846 (IAN). Rio Maicuru, Cateia, 15/VII/1957, G.A. Black 57-20.133 (IAN).

7. Axonopus chrysoblepharis (Lag.) Chase, Proc. Biol. Soc. Wash. 24: 134. 1911.

Cabrera chrysoblepharis Lag., Gen. Sp. Pl. 5. 1816.

Fig. $1 \mathrm{~g}$.

Duração indefinida, decumbente $30-50 \mathrm{~cm}$ alt., glabra; prefoliação convoluta; geralmente 2 inflorescências por colmo, pedúnculo 4-8, geralmente
3-8 racemos, 3-5cm compr., raque com cavidades onde se inserem as espiguetas e margens com tricomas amarelos do comprimento da espigueta ou maiores; espigueta glabra, 0,9-1,2mm compr., 2 nervuras submarginais, gluma superior e lema estéril subiguais, lema e pálea férteis pardos, do comprimento da espigueta, ápices glabros.

Distribuição geográfica: Guatemala, Costa Rica, Panamá, Trinidad, Guiana Francesa, Paraguai, Venezuela, Colômbia, Peru, Bolívia e Brasil (MA, CE, PI, PB, MG, GO, MT, PA, PR e SP).

Material examinado: BRASIL. Pará: Estreito, Marabá, 4/IV/1974, G.S. Pinheiro \& J.F.V. Carvalho 63 (IAN). Estreito, Marabá, 6/IV/1974, G.S. Pinheiro \& J.F.V. Carvalho 255 (IAN).

8. Axonopus compressus (Sw.) P. Beauv., Ess. Agrostogr. 12, 154. 1812.

Milium compressum Sw., Prodr. 24. 1788.

Fig. $1 \mathrm{~h}$.

Perene, cespitosa e estolonífera, até $60 \mathrm{~cm}$ compr., glabra; lâminas curtas e largas $2-10 \mathrm{~cm}$ compr., 0,7-1 mm larg., inflorescência 2-5, pedúnculo até $40 \mathrm{~cm}$ compr., eixo até $5 \mathrm{~cm}$ de compr., 2-3 racemos subconjugados ou digitados, $2,5-12 \mathrm{~cm}$ compr.; raque triquetra escabrosa; espigueta $2,5-3 \mathrm{~mm}$ compr., geralmente 4-nervadas, inconspícuas, alternadas por fileiras de tricomas curtíssimos, agudas ou apiculadas, lema e pálea férteis menores que a espigueta, com ápices levemente pubescentes.

Distribuição geográfica: Uruguai até USA, África, Ásia, Austrália.

Material examinado: BRASIL. Pará: Soure, 4/1950, Spruce 2669 (MG). Marabá, Serra dos Carajás, 20/III/1984, A.S.L. da Silva et al. 1923 (MG). Paragominas, 2/III/1980, T. Plowman et al. 9470 (MG). Moju, 11/1913, A. Goeldi 15078 (MG). Belém, Mosqueiro, 15/VI/1934, Swallen 4885 (MG). Santarém, Cacaual Grande, 10/1950, G.A. Black \& P. Ledoux 50-10318(IAN). Vigia, 23/I/1950, G.A. Black 50-870 (IAN). Ilha do Marajó, Fazenda São Pedro, 4/VI/1944, J. Swallen 6976 (IAN).

9. Axonopus eminens (Nees) G. A. Black, Advancing Frontiers Pl. Sci. 5: 92.1963.

Paspalum eminens Nees, Agrost. Brasil. 2: 30. 1829.

Fig. 1 i.

Perene, cespitosa, glabra, 1-2m alt.; inflorescência solitária, pedúnculo até $70 \mathrm{~cm}$ compr., eixo $10-30 \mathrm{~cm}$ compr., 5-20 racemos, $5-17 \mathrm{~cm}$ compr.; espigueta 
1,7-2,0mm compr., 0,5-08mm larg., 5-nervadas, glabra; lema e pálea férteis brancos do comprimento da espigueta, com ápices glabros.

Distribuição geográfica: Suriname, Bolívia e Brasil (PA, MA e GO).

Material examinado: BRASIL. Pará: Monte Alegre, 11/V/1953, D. Lima 53-1555 (IAN). BOLÍVIA. La Paz: Tipuani, Road, sem data, Buchtien, 7130 (IAN, Parátipo de A. eminens var. bolivianus G.A. Black)

10. Axonopus equitans Hitchc. \& Chase, Contr. U.S. Natl. Herb. 18(7):301. 1917.

Fig. $1 \mathrm{j}$.

Perene, cespitosa, glabra, ca. 1m alt.; 1-2 inflorescências por colmo, pedúnculo até $30 \mathrm{~cm}$ compr., eixo $4-5 \mathrm{~cm}$ compr., 4 racemos, $8-15 \mathrm{~cm}$ compr., raque flexuosa, glabra, com margem diminuta escabrosa; espigueta 2,3-2,4mm compr., $1 \mathrm{~mm}$ larg., 5-nervadas, gluma superior e lema estéril iguais; lema e pálea férteis 2,1-2,2mm compr., com ápices pubescentes.

Distribuição geográfica: Brasil, Guianas, Trinidad e Venezuela.

Material examinado: TRINIDAD. Port of Spain, 27/XI/1921, Hitchcock 9988 (IAN isótipo). BRASIL. Pará: Vigia, 22/I/1950, G.A. Black 50-8741, (IAN). Salvaterra, 4/IX/1969, E. Oliveira 4914 (IAN).

Axonopus equitans apresenta afinidades com $A$. pubivaginatus, diferenciando-se desta por apresentar espigueta púrpura escura e ápice da lamina foliar subagudo a obtuso.

11. Axonopus fissifolius (Raddi) Kuhlm., Comm. Lin. Telegr., Bot. 67 (Bot. 11): 87. 1922. 1823.

Paspalum fissifolium Raddi, Agrostogr. Bras. 26.

Fig. 11.

Perene, estolonífera, $20-60 \mathrm{~cm}$ alt.; inflorescência 2-5, pedúnculo 5-25cm compr., eixo curto, 2-5 racemos conjugados ou subdigitados, $3-7 \mathrm{~cm}$ compr.; raque triquetro com margem escabrosa, pouco pilosa na base; espigueta estreito-lanceolada, 1,6-2,0 $\mathrm{mm}$ compr., 0,5-0,6mm larg., 2-nervadas, com 2 fileiras de tricomas inconspícuos entre elas, lema fértil 0,1-0,4 mais curto que a espigueta, pubescente no ápice, branco ou amarelo-pálido.

Distribuição geográfica: das Guianas à Argentina e Brasil (AP, AM, PA, MT, BA, MG, RJ, SP, PR e RS).

Material examinado: BRASIL. Pará: Belém, 11/1913, A. Goeldi 1481 (MG). Belém, 29/XI/1956,
G.A. Black 56-18915 (MG). Belém, 20/III/1955, G.A. Black 55-18.136 (IAN). Monte Dourado, Rio Jari, 1/XI/1968, N.T. Silva 1054 (IAN). Belém, Utinga, 19/IX/1945, J.M. Pires \& G.A. Black 200 (IAN). Belém, 18/VII/1975, J.M. Pires 16001 (IAN).

Foram encontradas amostras de A. fissifolius erroneamente identificadas como A. affinis Chase.

12. Axonopus hitchcockii G.A. Black, Advancing Frontiers Pl. Sci. 5: 106. 1963.

Fig. $1 \mathrm{~m}$.

Perene, cespitosa, esparsa a densamente pilosa, até $1,5 \mathrm{~m}$ alt.; lâmina foliar com ápice fortemente atenuado; 1-2 inflorescência por colmo, pedúnculo 40-70cm compr., eixo 4-7cm compr., 2-10 racemos, $12-30 \mathrm{~cm}$ compr., raque triquetra pubescente; espigueta 3-4mm compr., 0,7-0,9mm larg., 5-7 nervadas, pubescente entre as nervuras; lema e pálea férteis 2-2,4mm compr., amarelo pálido a branco, com ápices pubescentes.

Distribuição geográfica: Guiana Inglesa e Brasil (AM e PA).

Material examinado: BRASIL. Pará: Bom Jardim, Rio São Miguel, 2/I/1952, J.M. Pires 3755 (Parátipo IAN) Jacareacanga, Alto Tapajós, 15/XII/1951, J.M. Pires 3512 (Parátipo IAN).

Axonopus hitchcockii é próxima de A. pubivaginatus e A. surinamensis (Hochst. Ex Steud.) Henr., diferindo, da primeira, basicamente pelo tamanho do lema e pálea férteis em relação à espigueta; da segunda, pela pilosidade e ápice da lâmina foliar.

13. Axonopus hoehnei G.A. Black, Advancing Frontiers Pl. Sci. 5: 143, f. 9. 1963.

Fig. $1 \mathrm{n}$.

Perene, glabra, ca. $1 \mathrm{~m}$ alt.; inflorescência solitária, pedúnculo até $45 \mathrm{~cm}$ compr., eixo até $5 \mathrm{~cm}$ compr., cerca de 12 racemos, 5-12cm compr.; raque flexuosa, glabra, com margem diminuta, escabrosa; espigueta 1,7-1,8mm compr., 2-3-nervadas, gluma superior e lema estéril subiguais; lema e pálea férteis castanho-escuro brilhantes do comprimento da espigueta, com ápices pubescentes.

Distribuição geográfica: Brasil (PA).

Material examinado: BRASIL. Pará: Rio Tapajós, Lageado, 2/1912, F.C. Hoehne 5310 (Holótipo IAN). Rio Tapajós, Lageado, 2/1912, F.C. Hoehne 5309 (Parátipo IAN).

Axonopus hoehnei é próxima de A. polydactylus, diferindo pela pilosidade da espigueta. 
14. Axonopus kaietukensis Swallen, Bull. Torrey Bot. Club 75: 83. 1948.

Fig. 10.

Perene, cespitosa, glabra, até $1 \mathrm{~m}$ alt.; inflorescência $1-2$, pedúnculo $30-50 \mathrm{~cm}$ compr., eixo 2,5-4cm compr., 10-20 racemos, $10-15 \mathrm{~cm}$ compr.; raque flexuosa; espigueta 1,3-2mm compr., pubescente ou glabriúscula, 2-nervadas; lema e pálea férteis castanho-escuros, brilhantes, do comprimento da espigueta, com ápices glabros.

Distribuição geográfica: Venezuela, Guiana e Brasil (AM e PA).

Material examinado: BRASIL. Pará: Alto Tapajós, Missão Velha, 20/VII/1959, W. Egler 984 (IAN).

Black (1963) citou apenas uma amostra de Axonopus kaietukensis para o Estado do Amazonas. No presente estudo foi encontrada, também, apenas uma amostra, sendo esta coletada no Pará e determinada por J.R. Swallen. Axonopus kaietukensis é próxima de A. flabelliformis Swallen, principalmente em relação ao hábito, sendo inclusive citada como sinônimo desta por Judziewicz (1990).

15. Axonopus leptostachyus (Flüggé) Hitchc., Contr. U.S. Natl. Herb. 22(6): 471. 1922.

Paspalum leptostachyum Flüggé, Gram. Monogr., Paspalum 122. 1810.

Fig. 1 p.

Perene, cespitosa, até $1,5 \mathrm{~m}$ alt., glabra; geralmente 2 inflorescências por colmo, pedúnculo até $75 \mathrm{~cm}$ compr., eixo até $15 \mathrm{~cm}$ compr., até 20 racemos, geralmente $2-6$, de $10-30 \mathrm{~cm}$ compr., raque triquetra com margem escabrosa, levemente pilosa na base; espigueta 2,8-3mm compr., 0,7-08mm larg., geralmente 2-nervadas, levemente pilosa; lema e pálea férteis amarelo-pálidos, 2/3 do comprimento da espigueta, ápices pubescentes.

Distribuição geográfica: de Trinidad à Argentina e Brasil (PA e GO).

Material examinado: BRASIL. Pará: Marabá, Serra dos Carajás, 21/III/1984, A.S.L. da Silva et al. 1872 (MG). Catéia, 15/VII/1957, G.A. Black 57-20144 (IAN). Vigia, 30/IX/1957, G.A. Black 48-3296 (IAN). Óbidos, 22/V/1957, G.A. Black et al. 57-19455 (IAN). Lago do Faro, 10/XI/1950, G.A. Black \& P. Ledoux 50-10640 (IAN).

Dentre as espécies estudadas, três apresentam lema fértil visivelmente menor que o lema estéril e gluma, sendo que destas, apenas A. leptostachyus apresenta gluma superior 2-nervadas, enquanto
A. centralis e A hitchcockii apresentam gluma superior mais de 2-nervadas.

16. Axonopus polydactylus (Steud.) Dedecca, Bragantia 15:273, f. 16. 1956.

Paspalum polydactylon Steud., Syn. Pl. Glumac. 1:19. 1855.

Fig. 1 q.

Perene, 1-1,2m alt., glabra ou levemente pilosa; inflorescência $1-2$, pedúnculo até $80 \mathrm{~cm}$ compr., eixo $3-10 \mathrm{~cm}$ compr., 5-30 racemos fasciculados, $10-30 \mathrm{~cm}$ compr., raque triquetra, glabra, mais estreita que a espigueta; espigueta $1,4-1,9 \mathrm{~mm}$ compr., $0,5-0,6 \mathrm{~mm}$ larg., com três a cinco tricomas rijos e pálidos que nascem junto ao ápice do pedicelo, atingindo até o meio da espigueta, espigueta 2-nervadas, glabra; lema e pálea férteis castanho-escuros, brilhantes, do comprimento da espigueta, ápices glabros.

Distribuição geográfica: Brasil (PA, MA, PI, CE, $\mathrm{RN}$, BA e PE).

Material examinado: BRASIL. Pará: Marapanim, 5/IV/1980, Davidse et al. 17900 (MG). Tucuruí, 17/III/1980, T. Plowman, N.A. Rosa \& C. Rosário 9663 (MG). Maracanã, 28/II/1975, L. Coradin 154 (MG).

Nos campos litorâneos do Estado, Axonopus polydactylus é uma das gramíneas mais freqüentes. Por apresentar algumas características em comum e pela grande variabilidade da espécie, suas amostras nos herbários visitados encontravam-se determinadas erroneamente como A. attenuatus (Presl) Hitchc., que na verdade é sinônimo de A. elegantulus (Presl.) Hitchc.

17. Axonopus pressus (Nees ex Steud.) Parodi, Notas Mus. La Prata, Bot. 3(17): 23. 1938.

Paspalum pressum Nees ex Steud., Syn Pl. Glumac 1:23.1855.

Fig $1 \mathrm{r}$.

Perene, cespitosa, glabra, ca. $1 \mathrm{~m}$ alt.; bainha com margem ciliada; inflorescência 1-2, pedúnculo $30-70 \mathrm{~cm}$ compr., eixo $3-10 \mathrm{~cm}$ larg., cerca de 36 racemos, $15-20 \mathrm{~cm}$ compr., raque triquetra, glabra, com margem diminuta, escabrosa; espigueta $2-2,7 \mathrm{~mm}$ compr., oblonga, 2-4-nervadas, revestida por tricomas pardacentos; gluma superior e lema estéril hialinos, pubescentes; lema e pálea férteis do comprimento da espigueta, castanhos, ápices glabros.

Distribuição geográfica: Paraguai e Brasil (PA, GO, MA, MT, MG, PR, RN e SP). 
Material examinado: BRASIL. Mato Grosso: Campo Grande, 7-11/II/1930, A. Chase 10836 (IAN, Holótipo de A. derbyanus var. derbyanus). Pará: Conceição do Araguaia, 21/II/1980, T. Plowman et al. 8988 (MG).

Foi encontrada apenas uma amostra de A. pressus nos herbários visitados, determinada como A. derbyanus G.A. Black. Neste trabalho, adotamos o conceito de Filgueiras (1995) que a considerou um sinônimo de $A$. pressus.

Dedecca (1956) afirma que $A$. pressus, a exemplo de A. polydactylus e A. attenuatus, pode apresentar tricomas junto ao ápice do pedicelo, sendo que nos indivíduos analisados neste trabalho tais estruturas não foram observadas.

18. Axonopus pruinosus Henr., Blumea 5:527, pl. 1945. Fig. $1 \mathrm{~s}$.

Perene, cespitosa, pilosa com tricomas esbranquiçados, até $2 \mathrm{~m}$ alt.; inflorescência 1-3, pedúnculo $30-90 \mathrm{~cm}$, eixo $10-20 \mathrm{~cm}$ compr., cerca de $10-20$ racemos, $5-15 \mathrm{~cm}$ compr., pilosos nas axilas, raque glabra ou glabriúscula com tricomas na base, mais estreita que a espigueta; espigueta $2,3-2,5 \mathrm{~mm}$ compr., 0,7-09mm larg., levemente pilosa entre as nervuras, 5-nervadas com as nervuras salientes; lema e pálea férteis branco amarelados, do comprimento da espigueta, com ápice pubescente.

Distribuição geográfica: Venezuela, Guiana Francesa e Brasil (PA e AC).

Material examinado: BRASIL. Acre: Rio Branco, Caracarai, sem data, Fróes 23615 (IAN, holótipo de A. caracarahyensis Black \& Fróes). Rio Branco, II/1910, Ule 8022 (Isótipo MG). Pará: Ariramba, 28/V/1957, G.A. Black et al. 57-19702 (IAN); Alto Ariramba, 9/XII/1910, A. Ducke in MG 11366 (MG); Ilha do Marajó, 1905, D.V. Miranda 7050 (MG); Rio Jaramacaru, Mutum, 28/V/1957, W.A. Egler 359 (MG).

Black (1963) citou erroneamente Axonopus pruinosus para o Estado do Amazonas (Ducke, in MG 11396), quando na verdade, em território brasileiro a espécie foi coletada apenas no Pará, com coletas nos campos do Marajó, campos do Ariramba, no alto Trombetas, e Acre.

Axonopus pruinosus é próxima de A. anceps (Mez) Hitchc., sendo inclusive consideradas como sinônimos por Judziewicz (1990).

19. Axonopus pubivaginatus Henr., Blumea 5(1): 276278, f. 1942.

Fig. $1 \mathrm{t}$.
Perene, cespitosa, $50-120 \mathrm{~cm}$ alt., glabra, pubescente; inflorescência $1-2$, pedúnculo $30-90 \mathrm{~cm}$ compr., eixo $2-10 \mathrm{~cm}$ compr., $8-20$ racemos, $5-20 \mathrm{~cm}$ compr., raque com margem escabrosa; espigueta 2,1-3,1 mm compr., 0,7-1 mm larg., 5-nervadas, pubescente entre as nervuras; lema e pálea férteis do comprimento da espigueta, amarelado pálido a branco, ápices pubescentes.

Distribuição geográfica: Colômbia, Guianas e Brasil (até Pernambuco).

Material examinado: SURINAME: 20/I/1936, $H$. Rombouts 395-H (IAN, holótipo de A. pubivaginatus var. pubivaginatus). BRASIL. Pará: Vigia, Campina da Palha, 21/I/1950, G.A. Black 50-8687 (IAN, holótipo de A. pubivaginatus var. tomentosus G.A. Black). Ilha do Marajó, Rio Camará, 3/1950, R. Lima 53 (IAN, holótipo de A. pubivaginatus var. limae G.A. Black). Faro, 31/I/1910, Ducke 10582 (MG). Santarém, Alter do Chão, 11/III/1909, Ducke 10284 (MG). Salvaterra, 25/XI/1988, A.S.L. da Silva \& C. Rosário 2150 (MG). Maracanã, Martins Pinheiro, 27/II/1975, L. Coradin 95 (IAN). Belém, 29/XI/1956, G.A. Black 18929 (IAN).

Axonopus pubivaginatus é muito próxima de A. equitans Hitchc. \& Chase. A amostra Black, 50-8741 (IAN) citada por Black (1963) como sendo A. pubivaginatus, permanecia determinada como A. equitans.

20. Axonopus purpusii (Mez) Chase, J. Wash. Acad. Sci. 17:144. 1927.

Paspalum purpusii Mez, Bot. Jahrb. Syst. 56(Beibl. 125): 10. 1921.

Fig. $1 \mathrm{u}$.

Perene, cespitosa, raro estolho, glabra ou levemente pilosa, até $50 \mathrm{~cm}$ alt.; lâminas com ápice obtuso; inflorescência 2-4, pedúnculo $20-45 \mathrm{~cm}$ compr., eixo 0-3,5cm compr., 4-10 racemos subdigitados ou fasciculados, $2-14 \mathrm{~cm}$ compr., raque com margem escabrosa, da largura da espigueta ou mais larga; espigueta elíptico-lanceolada, 1,7-2,0mm compr., 0,6-0,8mm larg., 2-4-nervadas, com fileiras de tricomas sedosos ao lado dos dois pares de nervuras; lema e pálea férteis pálidos, do comprimento da espigueta, com ápices pubescentes.

Distribuição geográfica: do Brasil ao México, Paraguai e Argentina.

Material examinado: BRASIL. Pará: Marajó, 8-18/II/1998, Costa Neto et al. 206 (MG). Marapanim, 3-4/IV/1980, G. Davidse et al. 17826 (MG). Vigia, 
29/III/1980, G. Davidse et al. 17587 (MG). Vigia, 6/VI/1976, P. Bolças \& J. Medeiros 92 (IAN). Bragança, 24/II/1977, U. Maciel \& P. Bolças 40 (IAN). Óbidos, 22/V/1957, G.A. Black et al. 57-19444 (IAN).

21. Axonopus scoparius (Flüggé) Kuhlm., Comm. Lin. Telegr., Bot. 67 (Bot. 11) 45-46. 1922.

Paspalum scoparium Flüggé, Gram. Monogr., Paspalum 124. 1810.

Fig. $1 \mathrm{v}$.

Perene, estolonífera, glabra, até $2 \mathrm{~m}$ alt.; inflorescência 1-3, pedúnculo até $1 \mathrm{~m}$ compr., eixo $15-25 \mathrm{~cm}$ compr., numerosos racemos fasciculados e agregados na extremidade, $10-25 \mathrm{~cm}$ compr., raque mais estreita que a espigueta; espigueta $2,2-2,4 \mathrm{~mm}$ compr., levemente pilosa, 5-nervadas, com as laterais muito próximas; lema e pálea férteis amarelados, do comprimento da espigueta, com ápices pubescentes.

Distribuição geográfica: do México ao Peru e Brasil (PA, MG, RJ e SP).

Material examinado: BRASIL. Pará: Belém, 9/I/1952, G.A. Black 52-14121 (IAN). Belém, 25/VII/1955, G.A. Black 55-18481 (IAN). Belém, 11/IX/1949, G.A. Black 49-8171 (IAN). Bom Jardim, Rio São Miguel, 2/I/1952, J.M. Pires 3755 (IAN).

22. Axonopus siccus (Nees) Kuhlm., Comm. Lin. Telegr., Bot. 67(Bot. 11):87. 1922.

Paspalum siccum Nees, Fl. Bras. Enum. Pl. 2:28. 1829.

Fig. $1 \mathrm{x}$.

Perene, até $1,5 \mathrm{~m}$ alt., glabra ou glabrescente; inflorescência 1-2, pedúnculo até $50 \mathrm{~cm}$ compr., eixo $3-15 \mathrm{~cm}$ compr., até 30 racemos de $4-10 \mathrm{~cm}$ compr., raque triquetra, mais estreita que a espigueta, margem escabrosa; espigueta 1,6-2mm compr., 0,6-0,7mm larg., 5-nervadas, com nervuras salientes, glabra, lema e pálea férteis branco amarelados, do comprimento da espigueta, ápices glabros.

Distribuição geográfica: Brasil, Paraguai, Uruguai e Bolívia.

Material examinado: BRASIL. Pará: Conceição do Araguaia, 20/II/1980, T. Plowman et al. 8950 (MG). Rio Curuá, 4/VIII/1981, J. Strudwick et al. 4028 (MG).

Os dados obtidos neste levantamento foram confrontados com estudos realizados sobre o gênero Axonopus com espécies brasileiras. Como resultado desta análise são apontadas oito novas ocorrências para o Estado (A. derbyanus, A. brasiliensis, A. centralis, A. chrysoblepharis, A. equitans, A. polydactylus, A. kaietukensis e A. siccus) e destas, duas também são novidades para o Brasil (A. centralis e A. equitans).

$\mathrm{Na}$ atualização nomenclatural dos binômios levantados, duas espécies encontravam-se determinadas por sinônimos: A. aureus $=$ A . canescens (Nees in Trin.) Pilger, A. chrysites (Steud.) Kuhlm., A. pulcher Kuhlm. e A. sprucei G.A. Black; A. pruinosus $=$ A. anceps (Mez) Hitchc.

Axonopus longispicus (Doell) Kuhlm., A. pellitus (Nees) Hitchc., A. senescens (Doell) Henr. e A. swallenii G.A. Black foram citadas para o Estado do Pará, mas não foram incluídas neste trabalho, uma vez que suas amostras não foram encontradas nos herbários visitados. Porém, destas, Judziewicz (1990) citou A. hitchcockii como sinônimo de A. longispicus, e Dedecca (1956) citou A. longipicus como espécie afim de $A$. leptostachyus, na qual pode ser provavelmente incluída.

Axonopus pellitus e A. senescens foram citadas por Dedecca (1956) para o Estado do Pará, mas nenhum material de referência é citado; já $A$. swallenii foi citada apenas por Black (1963, obra Princeps), (Swallen 3258, US). Por não se ter tido acesso ao material-tipo ou qualquer outra amostra, decidiu-se por não incluí-las neste trabalho.

Dentre as coleções examinadas, uma espécie, coletada na Serra do Cachimbo, não foi identificada (IAN 91565, 91866, 91540). Pelas características morfológicas, estas exsicatas diferem bastante das espécies conhecidas para o Brasil. Os espécimes apresentam 7-18 racemos, ca. $12 \mathrm{~cm}$ compr.; espiguetas 2,0-2,1 mm compr., $1 \mathrm{~mm}$ larg., bastante pubescentes, 2-3-nervadas. Lema e pálea férteis avermelhados, com ápice do lema fértil ligeiramente apiculado (Fig. 1 z.). Considera-se prematura a descrição formal de uma nova espécie, uma vez que há necessidade de se ter conhecimento mais abrangente do gênero para tomar tal decisão.

\section{Agradecimentos}

Ao CNPq, pela concessão de bolsa DCR ao primeiro Autor; aos Assessores e à Editora de Área de Fanerógamas, Dra. Silvia T.S. Miotto, pelas valiosas correções e sugestões.

\section{Referências bibliográficas}

Bastos, M.N.C. 1991. A flora rupestre da Serra dos Carajás (Gramineae). II. Gênero Axonopus P. Beauv. Boletim do Museu Paraense Emílio Goeldi; Série Botânica 7(2): 473-483. 
Black, G.A. 1963. Grasses of the genus Axonopus. Advancing Frontiers of Plant Science 5(1): 1-186.

Clayton, W.D. \& Renvoize, S.A. 1986. Genera Graminum. Grasses of the World. Royal Botanic Garden (Kew Bulletin Additional Series, 13), London.

Cremers, G. \& Hoff, M. 1993. Inventaire taxonomique des plantes de la Guyene Française III. Les Cyperaceae et les Poaceae. Muséum National d'Histoire Naturelle (Collection Patrimoines Naturels, série Patrimoine Genétique, v. 11), Paris.
Dedecca, D.M. 1956. As espécies brasileiras do gênero Axonopus (Gramineae) Bragantia 15 (19): 251-296.

Filgueiras, T.S. 1995. Flora dos Estados de Goiás e Tocantins: coleção Rizzo v. 17, Gramineae (Poaceae) Goiania.

Judziewicz, E.J. 1990. Poaceae (Gramineae). Pp. 82-112. In: A.R.A. Gorts - Van Rijn (ed.). Flora of the Guianas. Koeltz Scientific Books, Alemanha.

Renvoize, S.A. 1984. The Grasses of Bahia. Royal Botanic Gardens, Kew. 